\title{
NOTICIÁRIO
}

\section{Nota preliminar sobre a coleção malacológica "Eliseo Duarte"}

Dom Eliseo Duarte 86 anos, uruguaio e apaixonado por conchas. Quando ainda menino, recebia de seu avô uma concha, para que escutasse o "barulho do mar". Tratava-se de uma das espécies comuns nas praias uruguaias, mas estava dado o primeiro passo na rotina de um colecionador apaixonado, que passou grande parte de sua vida dedicando amor às conchas.

Sem noções científicas e sem grandes estudos, foram sendo somadas peças e mais peças encontradas nas costas uruguaias.

Alguns anos mais tarde, entrava Dom Eliseo em contato com José Castellanos, advogado de Havana, que pertencia à "Sociedad Malacológica Carlos de La Torre". O envio para Castellanos de espécimes coletados nas praias do Uruguai era recompensado com o correspondente dado científico referente ao material enviado, bem como o acréscimo de novas espécies à coleção de Dom Eliseo.

Através deste tipo de intercâmbio, foi travando conhecimento com muitos outros malacólogos em âmbito internacional; os lotes com espécies de todo mundo começaram a chegar para a coleção deste entusiasmado colecionador.

Mais tarde, por volta de 1957, descobria Dom Eliseo que outras pessoas no Uruguai tinham os mesmos interesses, surgindo daí a "Sociedad Malacológica del Uruguay".

Recentemente, devido a sua idade avançada, "Don" Eliseo como é conhecido por seus inúmeros amigos, procurou colocar sua coleção em uma Entidade científica, onde pudesse ser útil; naturalmente, procurou obter alguma recompensa pecuniária pelos seus longos anos de dedicação e labor.

Em 1978, a coleção era examinada por pesquisadores da FZB, e iniciava-se a tentativa de aquisição. Em setembro de 1980, finalmente, a coleção chegava, por iniciativa de José Willibaldo Thomé e com recursos do Conselho Nacional de Desenvolvimento Científico e Técnológico - CNPq (Processo n. ${ }^{\circ}$ 40.3205/79), a ser incorporada ao acervo do patrimônio natural do país, ficando sob custódia da Fundação Zoobotânica do Rio Grande do Sul.

A coleção compreende oficialmente 16.000 lotes de moluscos. Não estava catalogada, mas obedecia aos requisitos de uma coleção científica, pois seus lotes, além de bem acondicionados, estavam acompanhados de etiquetas com dados de identificação, procedência, coletor e data, entre outros. A maioria foi identificada e enviada por malacólogos altamente qualificados.

A coleção é valíosa pelo número de exemplares, pela sua raridade e beleza; científica, pela exatidão dos dados de identificação e procedência, variedade específica, lotes com numerosos espécimes; enriquece o patrimônio científico do país, devido à quantidade de material continental neotropical e material marinho procedente da costa sul-brasileira, uruguaia e argentina, que contém.

A coleção de conchas, sob a denominação de "Coleção Malacológica Eliseo Duarte", está sendo catalogada e deverá fazer parte do banco de dados do patrimônio natural regional. Foi recebida acondicionada em 36 caixas. As caixas vêm rotuladas com conteúdo vago, como moluscos terrestres, moluscos fluviais, moluscos marinhos, bivalvos e univalvos fluviais e marinhos. Tendo em vista os trabalhos predominantes no setor de Malacologia do MCN está se dando preferência, na abertura, às caixas contendo material terrestre e dulciaquícola. Isto ficará demonstrado em resultados relatados a seguir. O trabalho que ainda está se desenvolvendo para catalogação da coleção, caracteriza-se por ser bastante delicado, devido à antiguidade de muitas etiquetas, que já mostram, com bastante sinais, a passagem dos anos; quer também pela necessidade de correção de nomes científicos, bem como pela atualização e precisa identificação dos locais de coleta.

A maioria das etiquetas, estando preenchidas em idiomas estrangeiros variados, requer um trabalho de investigação cuidadoso para tradução e transcrição adequadas. 
Até o momento, foram catalogados 1.296 lotes, com aproximadamente 7.000 espécimes. O trabalho inicia-se com a abertura das caixas que contém os lotes, passando pela leitura e tradução dos dados das etiquetas e sua atualização, e lançamento no catálogo; segue-se a numeração individualizada das conchas, preenchimento de nova etiqueta padronizada, tudo a tinta nanquim; finalmente o reacondicionamento, com etiquetas antigas e novas e distribuição nos armários próprios, em disposição filogenética. Usamos para os gastrópodes a sistemática proposta por Taylor \& Sohl (1962), e para as demais classes, Thiele (1931/5).

Os armários foram patrocinados pela Fundação de Amparo à Pesquisa do Estado do Rio Grande do Sul - FAPERGS - (Processo n. ${ }^{\circ}$ 28.879). São 8 unidades com 272 gavetas, de formato padronizado.

Os 1.296 lotes já catalogados provêm, em grande parte, da região Neotropical, seguindo-se um percentual semelhante na região Paleártica; juntas representam mais de $2 / 3$ do total dos lotes trabalhados (Tab.).

Os lotes abrangem espécies distribuídas em 88 famílias; 100 lotes não estão ainda identificados. Encontram-se à disposição dos especialistas para estudo. Relacionamos a seguir, em ordem alfabética, as famílias representadas, com indicação do número de lotes e de espécimes respectivos. Julgamos que essa divulgação será de utilidade aos pesquisadores nacionais.

\begin{tabular}{|c|c|c|}
\hline Família & N. ${ }^{\circ}$ lotes & N. espécimes \\
\hline Acavidae & 23 & 50 \\
\hline Achatinidae & 08 & 14 \\
\hline Achatinellidae & 06 & 30 \\
\hline Adeorbidae & 01 & 07 \\
\hline Aloididae & 01 & 03 \\
\hline Amastridae & 06 & 20 \\
\hline Ampullariidae & 29 & 46 \\
\hline Ancylidae & 07 & 54 \\
\hline Ariophantidae & 04 & 07 \\
\hline Assimineidae & 02 & 07 \\
\hline Bradybaenidae & 32 & 49 \\
\hline Buccinidae & 01 & 02 \\
\hline Bulimulidae & 103 & 386 \\
\hline Camaenidae & 55 & 122 \\
\hline Capulidae & 01 & 01 \\
\hline Cerionidae & 10 & 62 \\
\hline Cerithiidae & 02 & 16 \\
\hline Chilinidae & 12 & 123 \\
\hline Chlamydephoridae & 01 & 01 \\
\hline Chondrinidae & 18 & 138 \\
\hline Clausiliidae & 51 & 235 \\
\hline Cochlicopidae & 05 & 56 \\
\hline Conidae & 01 & 03 \\
\hline Cyclophoridae & 29 & 154 \\
\hline Ellobiidae & 17 & 117 \\
\hline Endodontidae & 15 & 168 \\
\hline Enidae & 09 & 50 \\
\hline Ferussaciidae & 04 & 299 \\
\hline Ferrussaciidae & 03 & 13 \\
\hline Fruticicolidae & 01 & 08 \\
\hline Hadridae & 05 & 07 \\
\hline Haplotrematidae & 01 & 01 \\
\hline Helicarionidae & 02 & 03 \\
\hline
\end{tabular}




\begin{tabular}{|c|c|c|}
\hline Família & N.o lotes & N. ${ }^{\circ}$ espécimes \\
\hline Helicidae & 158 & 675 \\
\hline Helicinidae & 22 & 78 \\
\hline Helminthoglyptidae & 20 & 72 \\
\hline Hydatinidae & 01 & 01 \\
\hline Hydrobiidae & 82 & Muitos \\
\hline Ischnochitonidae & 01 & 14 \\
\hline Lacunidae & 01 & 26 \\
\hline Lamellariidae & 01 & 02 \\
\hline Latiidae & 01 & 01 \\
\hline Lavigeriidae & 01 & 01 \\
\hline Littorinidae & 02 & 15 \\
\hline Limacidae & 01 & 01 \\
\hline Lymnaeidae & 21 & 281 \\
\hline Melaniidae & 47 & 266 \\
\hline Muricidae & 01 & 01 \\
\hline Modulidae & 01 & 34 \\
\hline Mytilidae & 03 & 04 \\
\hline Neritidae & 09 & 40 \\
\hline Odontostomidae & 22 & 90 \\
\hline Oleacinidae & 03 & 18 \\
\hline Orculidae & 06 & 12 \\
\hline Orthalicidae & 07 & 09 \\
\hline Philomycidae & 01 & 01 \\
\hline Physidae & 18 & 96 \\
\hline Planaxidae & 01 & 02 \\
\hline Planorbidae & 77 & 649 \\
\hline Pleurodontidae & 02 & 16 \\
\hline Polygyridae & 23 & 93 \\
\hline Pomatiasidae & 35 & 132 \\
\hline Potamididae & 03 & 17 \\
\hline Psammobiidae & 01 & 03 \\
\hline Pupillidae & 06 & 63 \\
\hline Pyramidellidae & 01 & 08 \\
\hline Retusidae & 01 & 01 \\
\hline Rhytididae & 03 & 05 \\
\hline Rissoidae & 02 & 11 \\
\hline Scalidae & 01 & 01 \\
\hline Sphaeriidae & 13 & 43 \\
\hline Spirulidae & 01 & 07 \\
\hline Subulinidae & 14 & 174 \\
\hline Succineidae & 14 & 93 \\
\hline Streptaxidae & 07 & 18 \\
\hline Systrophiidae & 04 & 20 \\
\hline Testacellidae & 01 & 03 \\
\hline Tornatellinidae & 02 & 07 \\
\hline Trochidae & 01 & 01 \\
\hline Turbinidae & 02 & 06 \\
\hline Urocoptidae & 28 & 96 \\
\hline Urocyclidae & 01 & 02 \\
\hline Valloniidae & 09 & 82 \\
\hline Valvatidae & 07 & 21 \\
\hline Vertiginidae & 09 & 60 \\
\hline Vitrinidae & 01 & 02 \\
\hline Viviparidae & 14 & 50 \\
\hline Zonitidae & 17 & 71 \\
\hline Não identificadas & 100 & 340 \\
\hline
\end{tabular}




\section{Observação:} os lotes:

Foi possível notar, até agora, a presença de espécimes significativos entre

- 12 lotes de topótipos: Ampullariidae (1), Bulimulidae (5), Cyclophoridae (1), Helicidae (2), Helicinidae (1), Sphaeriidae (1), Urocoptidae (1).

- 3 lotes de parátipos: Sphaeriidae (1), Bulimulidae (2):

Lote N.o MCN 10.285 - Eupera doellojuradoi Klappenbach, 1962, Salto Chico, rio Uruguai, Departamento de Salto, Uruguai, leg. Ariel Sclavi, iii.1957 - (1 valva).

Lote N.o MCM 10.521 - Mostryx (Bostryx) vilchezi Weyrauch, 1960 Socota, Peru (20 km NO de Cutervo, alt. $1.950 \mathrm{~m}$, no vale do rio Guinemaya), leg. W. Weyrauch (5 exemplares - ex. coll. W. W. - 2009).

Lote N. ${ }^{\circ}$ MCN 10.677 - Cyclodontina (Spixia) corderoi Klappenbach, 1958, Pozo Hondo, Tambores, Departamento Tacuarembó, Uruguai, leg. M. A. Klappenbach \& Pablo R. San Martin, 12.x.1957 (8 exemplares).

\section{DISTRIBUIÇÃO DOS PRIMEIROS 1.296 LOTES CATALOGADOS DA COLEÇÃO ELISEO DUARTE:}

\begin{tabular}{lcc}
\hline REGIÃO & N. ${ }^{\circ}$ LOTES & $\begin{array}{c}\text { PERCENTUAL } \\
(\%)\end{array}$ \\
\hline NEOGRÁFICA & 506 & 39,0 \\
Peotropical & 427 & 32,9 \\
Neártica & 153 & 11,8 \\
Australiana & 137 & 10,6 \\
Oriental & 53 & 4,1 \\
Etiópica & 20 & 1,5 \\
\hline
\end{tabular}

Jorge A. Barcelos de Menezes José Willibaldo Thomé (Fundação Zoobotânica do Rio Grande do Sul) 